\title{
TRANSLITERATION AND TRANSLATION
}

The conversations, articles, and television programs referred to in this work were originally heard or read in French, the Moroccan dialect of Arabic, or the Modern Arabic employed in the press. Unless otherwise noted, all translations are my own; the notes also cite published English translations.

In Morocco, many Arabic words have standard transliterations in the Latin alphabet; I have employed these when possible. Otherwise, I have relied on A Dictionary of Moroccan Arabic, edited by Richard S. Harrell and Harvey Sobelman. However, I have indicated only those emphatic letters included in the Arabic alphabet and have simplified the vowels in ways that will, I hope, facilitate pronunciation for English-speaking readers. Long vowels are indicated by macrons.

The following list gives approximate pronunciations for phonemes unfamiliar to most English-speaking readers:

? A glottal stop, similar to the sound $e h$

d Emphatic $d$

g Similar to the French $r$ ( $r$ grasseyé)

$\dot{h}$ Similar to the English $h$ in "home"

$H \quad$ Similar to the English $h$ but emphatic

$q \quad$ Similar to the English $q$ pronounced deep in the throat

$q \quad$ Like the English $g$ in "good" 
$r \quad$ Like the Spanish rolled $r$

$\bar{s} \quad$ Similar to the English sh in "shoe"

$s \quad$ Emphatic $s$ (like English "sod")

$x \quad$ Like the German ch in "Bach"

c A sound made at the back of the throat, unlike any sound in English 